\title{
Argyrophilic nucleolar organizer regions of thyroid lesions on fine needle aspiration smears
}

\author{
Chalise $\mathrm{S}^{1}$, Thapa $\mathrm{S}^{2}$, Sayami G ${ }^{2}$, Shrestha $\mathrm{A}^{2}$ \\ 'Department of Pathology, kathmandu Medical college, Kathmandu, Nepal \\ ${ }^{I}$ Department of Pathlogy, Institute of Medicine, Kathmandu, Nepal
}

\section{Keywords:}

Fine needle aspiration cytology;

Nucleolar Organizer

Regions;

Thyroid

\begin{abstract}
Background: Argyrophilic nucleolar organizer region is higher in malignant nuclei as compared to reactive and benign nuclei. The main objective of this study was to evaluate the role of Argyrophilic nucleolar organizer region and its extent in differentiating benign and malignant lesions, particularly with respect to follicular neoplasms of the thyroid.

Materials and Methods: This was a prospective, cross sectional study which included 110 patients presenting with thyroid swelling. The fine needle aspiration smears were studied by conventional methods and silver staining for Argyrophilic nucleolar organizer region. In 50 cases, diagnosis was confirmed by histopathology. The Argyrophilic nucleolar organizer region count was done and the mean Argyrophilic nucleolar organizer region count per nucleus was calculated along with pattern of distribution.

Results: Mean Argyrophilic nucleolar organizer region count was higher in neoplastic as compared to non-neoplastic and inflammatory lesions. Papillary carcinoma had the highest mean Argyrophilic nucleolar organizer region count $(5.40 \pm 0.86)$ and the lowest count was seen in Hashimoto's thyroiditis $(2.10 \pm 0.36)$. Higher mean Argyrophilic nucleolar organizer region count was recorded in follicular carcinoma (4.84 \pm 1.42$)$ as compared to follicular adenoma $(3.5 \pm 0.27)$ which was found to be statistically significant $(\mathrm{P}<0.05)$. Argyrophilic nucleolar organizer region dots were arranged in clusters in colloid goiter whereas scattered discrete black dots were seen in neoplastic lesions.
\end{abstract}

Conclusion: Argyrophilic nucleolar organizer region study of thyroid can be used as an additional diagnostic adjunct with cytomorphological features to differentiate benign and malignant follicular neoplasms.

\section{INTRODUCTION}

Thyroid cancer accounts for approximately $1 \%$ of all malignancies in developed countries. Benign thyroid tumors are common, and although cancers are relatively rare, they represent the most common malignancies in the endocrine system. ${ }^{1}$ Nodular thyroid disease is indicated by the presence of single or multiple nodules within the thyroid

\section{Correspondence:}

Dr. Sanat Chalise, $M D$

Department of Pathology, Kathmandu Medical College, Kathmandu, Nepal E-mail: sanat_chalise@yahoo.com gland and remains a common diagnostic problem. ${ }^{2}$

Fine needle aspiration cytology (FNAC) is now accepted as an important aid in the investigation of thyroid nodules. The ease and safety with which the specimen can be obtained and the low cost of the technique ensure a place for fine needle aspiration (FNA) in the diagnostic evaluation. However, main difficulty is encountered in differentiating between follicular adenoma and follicular carcinoma in FNA because the two important distinguishing features, capsular and angioinvasion, cannot be assessed in FNA 
smears. $^{3}$

It is well known that silver staining technique for nucleolar organizer regions (NORs) has been successfully applied to a wide variety of neoplastic lesions to distinguish benign from malignant lesions. ${ }^{4}$ NORs are loops of DNA projecting into the nucleoli of the interphase nuclei and they are thought to encode for ribosomal RNA (rRNA). This rRNA is responsible for protein synthesis of the cell. As protein synthesis is required in the cell proliferation, a relation between NORs and cell proliferation is suggested. It has been acknowledged that number of NORs within nuclei is significantly higher in malignant cells than in normal, reactive or benign neoplastic cells. ${ }^{5}$

Silver nucleolar organizer region (AgNOR) staining technique permits the study of the number, size and shape of NORs. The amount of silver deposit in the cell, reflecting the amount of NORs that are involved in protein synthesis, is related to the proliferative activity of that cell. ${ }^{5}$ Therefore, the study of AgNOR may become an important parameter to study the aggressiveness of the lesions when most costly methods are not available. ${ }^{6}$

The role of AgNOR is already well established in the diagnosis of oral cavity tumors, breast lesions, lymphoma and prostatic tumors. ${ }^{7-9}$ However correlative studies of AgNOR staining with the cytomorphological features in FNAC of thyroid lesions are very few and inconsistent. ${ }^{3}$ Hence in the present study, utility of AgNOR staining in FNAC smears of thyroid lesions is analyzed in the context of its use in differentiating benign and malignant lesions.

\section{MATERIALS AND METHODS}

This was a prospective cross sectional study carried out from December 2009 to April 2011 in department of pathology. All the patients presented with thyroid swelling were included in the study. Inadequate material in aspiration (smears containing less than 100 well preserved cells) and smears in which cells were obscured by blood were excluded from the study. The FNA smears were studied by conventional methods and silver staining for AgNORs. Mean AgNOR count in non-neoplastic and neoplastic thyroid lesions were compared by taking colloid goiter as a normal control.

\section{Procedure for AgNOR staining}

Staining procedure was followed as described by Crocker et al. ${ }^{10}$.The stained smears were examined under oil immersion (1000X). AgNOR stained as black dots within the nucleus. Two parameters were then taken into consideration:

1.Average number of AgNOR dots per cell (Counting was done in 100 cells and mean AgNOR per nucleus was calculated).

2.Arrangement of AgNOR dots within the nuclei in each cells was assessed.

AgNOR dots were defined as clear black, homogenous silver precipitates with well defined edges. The dots were scattered around the nucleus as satellites or grouped together as clusters. AgNOR dots present in the cluster form in the nuclei were considered as one.

\section{Statistical analysis}

The SPSS version 18.0 software was used for statistical analysis. All discrete variables were expressed as

Table 1: Mean AgNOR count of thyroid lesions in FNAC

\begin{tabular}{|lccc}
\hline \multicolumn{1}{c}{ Cytodiagnosis } & $\begin{array}{c}\text { No. of } \\
\text { cases }\end{array}$ & Mean \pm SD & Range \\
\hline Colloid goitre & 35 & $2.64 \pm 0.63$ & $1.91-4.52$ \\
\hline Nodular goitre & 19 & $3.04 \pm 0.8$ & $2.41-5.96$ \\
\hline Hashimoto's thyroiditis & 12 & $2.10 \pm 0.36$ & $1.81-3.01$ \\
\hline Lymphocytic thyroiditis & 9 & $2.22 \pm 0.39$ & $1.56-2.91$ \\
\hline de Quervain's thyroiditis & 4 & $2.43 \pm 0.52$ & $2.01-3.12$ \\
\hline Papillary carcinoma & 16 & $5.40 \pm 0.86$ & $3.12-6.76$ \\
\hline Follicular neoplasm & 9 & $4.10 \pm 1.13$ & $3.22-6.96$ \\
\hline Anaplastic carcinoma & 3 & $3.89 \pm 0.53$ & $3.69-4.50$ \\
\hline Squamous cell carcinoma & 1 & 4.60 & 4.60 \\
\hline Hurthle cell neoplasm & 1 & 3.25 & 3.25 \\
\hline Medullary carcinoma & 1 & 4.31 & 4.31 \\
\hline
\end{tabular}

Table 2: Mean AgNOR count of neoplastic thyroid lesions and its correlation with histopathology

\begin{tabular}{|c|c|c|c|c|c|}
\hline Cytodiagnosis & No. & Histopathological diagnosis & No. & Mean \pm SD & Range \\
\hline \multirow[t]{2}{*}{ Follicular neoplasm } & 9 & Follicular adenoma & 5 & $3.5 \pm 0.27$ & $3.22-3.84$ \\
\hline & & Follicular carcinoma & 4 & $4.84 \pm 1.42$ & $3.98-6.96$ \\
\hline Hurthle cell neoplasm & 1 & Hurthle cell adenoma & 1 & 3.25 & 3.25 \\
\hline Papillary carcinoma & 16 & Papillary carcinoma & 12 & $5.40 \pm 0.86$ & $3.12-6.76$ \\
\hline Medullary carcinoma & 1 & Medullary carcinoma & 1 & 4.31 & 4.31 \\
\hline Anaplastic carcinoma & 3 & Anaplastic carcinoma & 4 & $4.07 \pm 0.56$ & $3.69-4.60$ \\
\hline Squamous cell carcinoma & 1 & & & & \\
\hline Total & 31 & & 27 & & \\
\hline
\end{tabular}


Table 3: Statistical comparison of mean AgNOR count of different thyroid lesions in FNAC diagnosis with colloid goitre

\begin{tabular}{lccc}
\hline \multicolumn{1}{c}{ Diagnosis } & Number & Mean \pm SD & P value \\
Nodular goiter & 19 & $3.04 \pm 0.8$ & 0.07 \\
\hline Hashimoto's thyroiditis & 12 & $2.10 \pm 0.36$ & 0.008 \\
\hline Lymphocytic thyroiditis & 9 & $2.22 \pm 0.39$ & 0.067 \\
\hline de Quervain's thyroiditis & 4 & $2.43 \pm 0.52$ & 0.535 \\
\hline Papillary carcinoma & 16 & $5.40 \pm 0.86$ & $<0.05$ \\
\hline Follicular neoplasm & 9 & $4.10 \pm 1.13$ & $<0.05$ \\
\hline Anaplastic carcinoma & 3 & $3.89 \pm 0.53$ & 0.002 \\
\hline Squamous cell carcinoma & 1 & 4.60 & 0.005 \\
\hline Hurthle cell neoplasm & 1 & 3.25 & 0.351 \\
\hline Medullary carcinoma & 1 & 4.31 & 0.014
\end{tabular}

Table No 4: Statistical comparison of follicular lesions with colloid goitre

\begin{tabular}{ccccc}
\hline \multicolumn{1}{c}{ Diagnosis } & Number & Mean \pm SD & P value & P value \\
\hline Follicular adenoma & 5 & $3.5 \pm 0.27$ & 0.05 & $>0.05$ \\
Follicular carcinoma & 4 & $4.84 \pm 1.42$ & $<0.05$ & NA
\end{tabular}

percentages and continuous variables as mean \pm SD. Significance of continuous variables was analyzed by using one-way analysis of variance (ANOVA) and $\mathrm{P}<0.05$ was considered to be statistically significant.

\section{RESULTS}

All together 2091 fine needle aspirations were done during the period of 16 months, of which $184(8.79 \%)$ cases were from thyroid. Among these 184 cases, only 110 cases were included in this study. Remaining 74 cases were disqualified because of inadequate sample in the smear and cells entangled within the blood. Eighty-four (76.36\%) of the patients were female and $26(23.64 \%)$ were male with male-to-female ratio being 1:3.2. Non-neoplastic (49.09\%) comprised the main bulk followed by neoplastic $(28.18 \%)$ and inflammatory $(22.73 \%)$ thyroid lesions. Age ranged from 13-72 yr with a maximum number of patients $(62.72 \%)$ being in the $21-40$ years age group. The mean age was 34.80 years. Common lesion found were colloid goiter and nodular goiter followed by papillary carcinoma.

Higher number of AgNOR dots were found in neoplastic lesions as compared to non-neoplastic and inflammatory lesions. The mean AgNOR count was highest in papillary carcinoma 5.40 \pm 0.86 (fig. 1) whereas lowest AgNOR count was seen in Hashimoto's thyroiditis 2.10 \pm 0.36 . Mean AgNOR count of thyroid lesions in FNAC are shown in Table 1.

The cytology diagnosis was confirmed histologically in 50 cases of which 27 cases were neoplastic. Among 9 cases diagnosed as follicular neoplasm in FNAC, 5 were diagnosed as follicular adenoma and 4 were diagnosed as follicular carcinoma in histopathology. AgNOR count was found to be higher in follicular carcinoma $4.84 \pm 1.42$ (fig.2) than in follicular adenoma $3.5 \pm 0.27$ (fig.3). Mean AgNOR count of neoplastic thyroid lesions and its correlation with histopathology are shown in Table 2.

AgNOR count was found to be statistically significant $(<0.05)$ in most of the neoplastic lesions. Table 3 and Table 4 shows statistical comparison of mean AgNOR count of different thyroid lesions in FNAC diagnosis with colloid goiter and statistical comparison of follicular lesions with colloid goiter respectively.

Inflammatory and non-neoplastic lesions showed overlaping between mean AgNOR counts; however only few overlaps were seen between neoplastic and other thyroid lesions (fig.4). No overlap of mean AgNOR count was seen between follicular adenoma and carcinoma (fig.5).

The AgNOR dots were arranged in clusters in colloid goiter (fig.6). Hurthle cell adenoma showed centrally located clusters of large dots within the nuclei (fig.7). No cluster arrangement was seen in other cases. All of the neoplastic lesions showed scattered discrete black dots (fig 1 \&2).

\section{DISCUSSION}

In thyroid neoplasms, ancillary techniques such as enzyme techniques, DNA measurements, immunocytochemistry and morphometric studies have been used with varying degree of success. ${ }^{4}$ AgNOR is one of such marker which seems highly sensitive and specific to distinguish between benign and malignant thyroid lesions in smears because more accuracy is ensured after whole nuclei have been assessed. $^{2}$

In the current study mean AgNOR count was highest in papillary carcinoma $(5.40 \pm 0.86)$ and lowest in Hashimoto's thyroiditis $(2.10 \pm 0.3)$. Asotra $\mathrm{S}$ also found highest mean AgNOR count in papillary carcinoma $(5.08 \pm 1.11)$ and lowest in Hashimoto's thyroiditis $(2.76 \pm 0.08) .^{2}$ Mehrotra A et al found highest mean AgNOR count in follicular carcinoma $(5.04 \pm 0.5)$ and lowest in case of thyroiditis $(1.37 \pm 0.4){ }^{3}$ Khan EM et al. found highest mean AgNOR count in follicular carcinoma $(2.85 \pm 0.54)$ and lowest in adenomatous goitre $(1.92 \pm 0.4) .{ }^{11}$

Mean AgNOR count of the thyroid lesions in our study showed low count in nodular colloid goitre $(3.04 \pm 0.8)$ as compared to follicular neoplasms $(4.10 \pm 1.13)$ with few overlaps between the cases. Asotra $\mathrm{S}^{2}$ also found significant difference in mean AgNOR count between nodular goitre $(2.82 \pm 0.088)$ and follicular neoplasms $(3.15 \pm 0.80)$ in their study.

After histopathological confirmation of the diagnoses, it was 


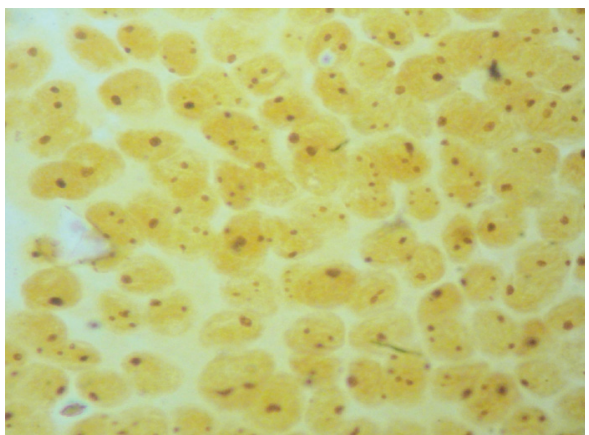

Figure 1: Papillary carcinoma showing scattered discrete black dots; Mean AgNOR count 4.6 (Silver stain X1000).

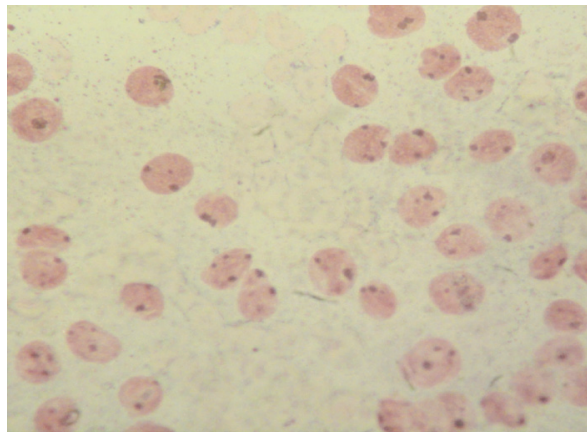

Figure 3: Follicular neoplasm showing scattered discrete AgNOR dots; Mean AgNOR count 3.5 (Silver stain $\times 1000$ ).

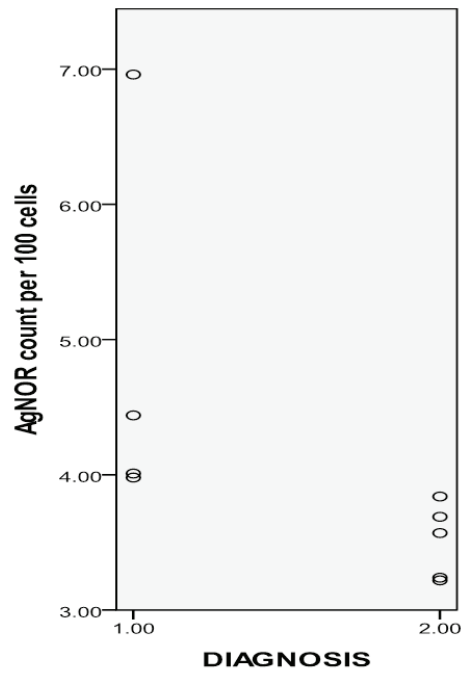

Figure 5: Scattergram showing mean number af AgNOR counts between follicular adenoma and carcinoma. 1.00: Follicular carcinoma, 2.00: Follicular adenoma

found that mean AgNOR count was higher in carcinoma than in adenoma. However there was overlap between some of the cases. Other studies done by Solymosi T et al. ${ }^{4}$, Astora $\mathrm{S}^{2}$ and Mehotra $\mathrm{A}^{3}$ also showed higher mean AgNOR count in carcinomas than adenomas. Camergo RS did not find any difference in mean AgNOR count between adenoma and carcinoma. ${ }^{12}$

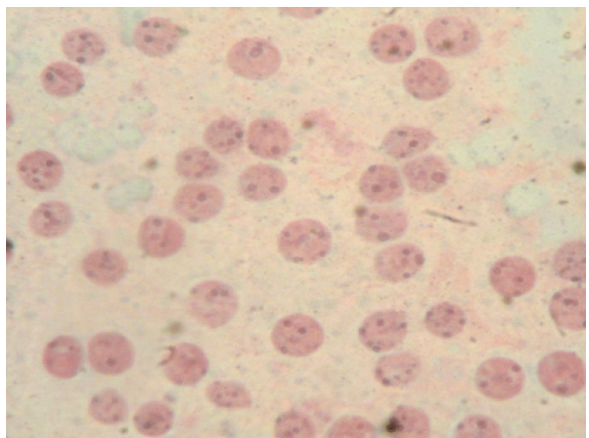

Figure 2: Follicular neoplasm showing scattered discrete AgNOR dots; Mean AgNOR count 5.2 (Silver stain X1000).

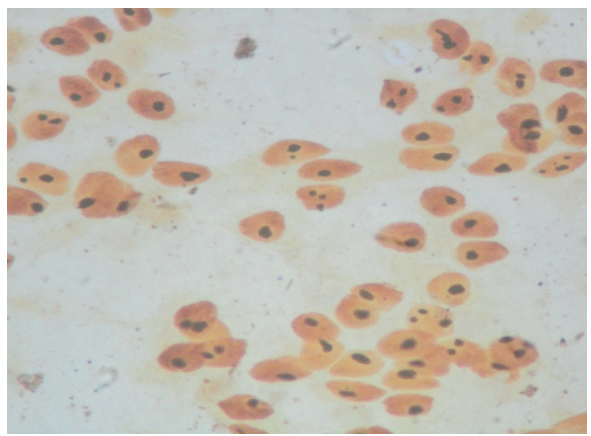

Figure 6: Colloid goitre showing clusters of AgNOR dots; Mean AgNOR count 1.9 (Silver stain X1000).

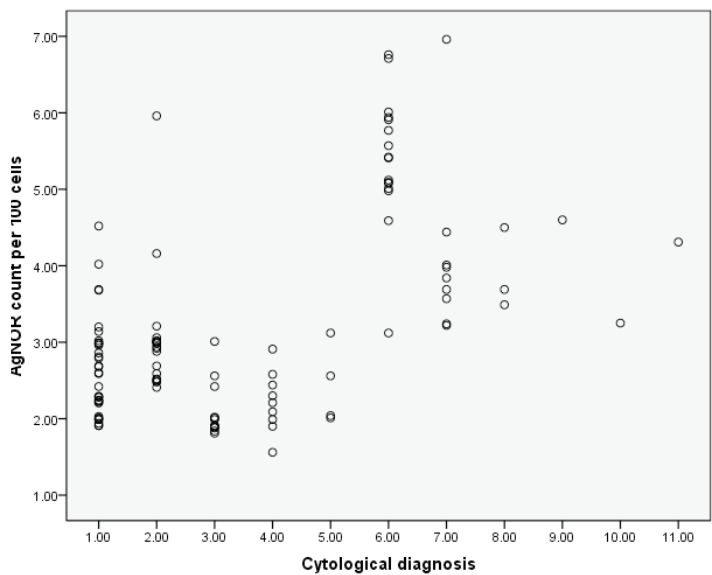

Figure 4: Scattergram showing mean number of AgNOR counts for each case.

1.00: Colloid goitre, 2.00:Nodular goitre, 3.00:Hashimoto's thyroiditis, 4.00: Lymphocytic thyroiditis, 5.00: de Quervain's thyroiditis, 6.00: Papillary carcinoma, 7.00: Follicular neoplasm, 8.00: Anaplastic carcinoma, 9.00: Squamous cell carcinoma, 10.00:Hurthle cell neoplasm, 11.00: Medullary carcinoma

Among the cases of follicular neoplasms, after histopathological confirmation of the diagnosis, higher mean AgNOR count was seen in follicular carcinoma (4.84 $\pm 1.42)$ than in follicular adenoma $(3.5 \pm 0.2)$. Astora $\mathrm{S}$ et al. also found a higher mean AgNOR count in follicular carcinoma $(2.84 \pm 0.56)$ than in follicular adenoma $(2.23$ $\pm 0.3) .{ }^{2}$ Mehotra A also recorded a higher mean AgNOR count in follicular carcinoma $(5.04 \pm 0.5)$ than in follicular 


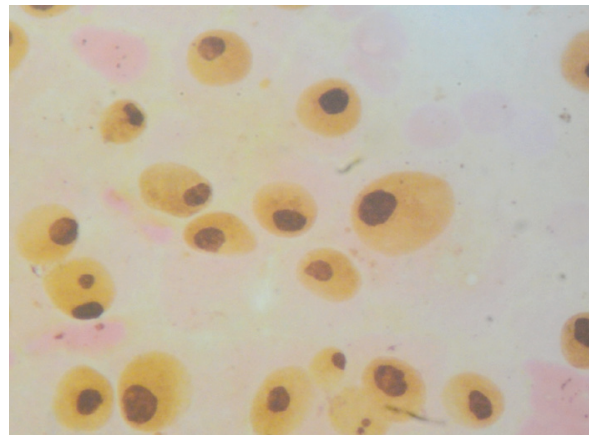

Figure 7: Hurthle cell neoplasm showing centrally located cluster of large AgNOR dots; Mean AgNOR count 3.2 (Silver stain X1000).

adenoma $(2.17 \pm 0.7){ }^{3}$

There was a statistically significant $(\mathrm{P}<0.05)$ difference in mean AgNOR count among carcinomas, adenomas and non-neoplastic lesions; however, no cut-off point could be ascertained to distinguish these groups because of overlapping. Mehrotra $\mathrm{A}^{3}$ and Arora $\mathrm{S}^{2}$ also found statistically significant $(\mathrm{P}<0.05)$ difference in mean AgNOR count between carcinomas and adenomas; however, due to overlapping, no cut-off point was established as well. Khan EM et al. in their study also did not find a cut-off point to differentiate between non-neoplastic and neoplastic lesions based on mean AgNOR count due to overlapping. ${ }^{11}$

Although this study found a higher mean AgNOR count in follicular carcinoma $(4.84 \pm 1.42)$ than in follicular adenoma $(3.5 \pm 0.27)$ and there was no overlapping in AgNOR counts between the two, cut-off point could not be established because the number of cases was too small. Karmaker T et al. observed a significant difference in AgNOR counts in follicular carcinoma and follicular adenoma, but they too had a small number of cases in their study. ${ }^{13}$

Asotra S in their study of silver stain in cytological preparation, showed a significant correlation $(<0.05)$ of AgNOR counts with benign and malignant lesions. ${ }^{2}$ A significant difference in AgNOR counts was also found in all benign and malignant groups in other studies done. ${ }^{3,14,15}$ However, Camargo RS et al did not find any significant difference in mean AgNOR count between benign and malignant thyroid lesions in their study and concluded that $\mathrm{AgNOR}$ count is an unreliable parameter to discriminate between benign and malignant thyroid lesions. ${ }^{12}$

Arrangements of AgNOR dots were not similar in benign and malignant lesions. In colloid goitre the dots were arranged in clusters. Few cases of Hashimoto's thyroiditis and colloid goitre with hyperplastic changes showed clustered arrangement. However, Hurthle cell adenoma showed centrally located clusters of large dots within the nuclei. All other neoplastic lesions showed scattered multiple clear dots. Studies done by Szot W et al. ${ }^{16}$ and Asotra $\mathrm{S}^{2}$ also found similar arrangement in almost all the lesions as in our study except in Hurthle cell adenoma where they found no cluster arrangement.

\section{CONCLUSION}

AgNOR count provides useful information in the assessment of thyroid lesions, particularly in the evaluation of solitary thyroid nodules. AgNOR also provides reliable information to differentiate between nodular goitre and follicular neoplasms. As it is not possible to differentiate between follicular adenoma and follicular carcinoma only on the basis of FNAC, AgNOR count can be utilized as an additional tool in the cytological evaluation of follicular neoplasms.

\section{REFERENCES}

1. Delellis RA, Williams ED. Thyroid and parathyroid tumors introduction. In: Delellis RA, Lloyd R, Heitz PU, Eng C, eds. World health organization classification of tumors pathology \& genetics tumors of endocrine organs. Lyon:IARC,2004. pp50.

2. Asotra S, Sharma J. Role of AgNORs in thyroid lesions on fine needle aspiration cytology smears. J Cytol 2008;25:18-22.

3. Mehrotra A, Agarwal PK, Chandra T. Cytopathology and AgNOR counts in fine needle aspiration cytology smears of thyroid lesions. Diagn Cytopathol 1998;19:238-43.

4. Solymosi T, Veronika T, Zoltan S, Bodo M, Gal I, Csanadi L. Diagnostic value of AgNOR method in thyroid cytopathology: correlation with morphometric measurements. Diagn Cytopathol 1996;14:140-4.

5. Hasnan J, Jayaram G. Nucleolar organizer regions distribution in fine needle aspiration cytological smears from breast lesions. Malays J Pathol 1996;18:35-41.

6. Khanna AK, Yadav SK, Dixit VK, Kumar M. AgNOR count and subjective AgNOR pattern assessment (SAPA) score in carcinoma of the pancreatic head including periampullary tumors. JOP. J Pancreas 2005;6:575-80.

7. Crocker J, Egan MJ. Correlation between NOR sizes and number in non-Hodgkin lymphomas. J Pathol 1988;156:233-9.

8. Contractor H, Ruschoff J, Hanisch T et al. Silver stained structures in prostatic carcinoma: evaluation of diagnostic and prognostic relevance by automated image analysis. Urol Int 1991;46:9-14.

9. Khanna AK, Datta G, Kumar M. Correlation of AgNOR with tumor size, stage of tumor, lymph node status and grade of tumor in oral cancer. In: Verma AK, editor. Oral Oncology IV B. MacMillan India: Banglore India;1995.pp:25-30.

10. Egan MJ, Crocker J: Nucleolar organizer regions in pathology. Br J Cancer 1992;65:1-7.

11. Khan EM, Pandey R. Differential diagnosis of fine needle aspiration smears of thyroid nodules: cytologic features and AgNORs. Acta Cytol 1996;40:959-62.

12. Camargo RS, Shirata NK, di Loreto C, Garcia EA, Castelo A, Longatto FA. Significance of AgNOR measurement in thyroid lesions. Anal Quant Cytol Histol. 2006;28:188-92.

13. Karmakar T, Dey P. Role of AgNOR in diagnosis of thyroid follicular neoplasms on fine needle aspiration smears. Diagn Cytopathol 1995;12:148-9.

14. Zaczek M, Szot W, Chlap Z. Argyrophilic nucleolar organizer regions in proliferative lesions of the thyroid gland. Anal Quant Cytol Histol 1996;18:1-8. 
15. Eroz R, Cucer N, Karaca Z, Unluhizarci K, Ozturk F. The evaluation of argyrophilic nucleolar organizing region proteins in fine needle aspiration samples of thyroid. Endocr Pathol 2011;22:74-8.
16. Szot W, Szybinski Z, Zaczek M et al. Fine needle aspiration cytology combined with argyrophilic nucleolar organizer regions (AgNORs) in diagnosis of thyroid neoplasms. Endokrynol Pol 1993;44:413-26. 